\title{
20 Years of Evolutionary Analysis of Giant Panda Habitat Using Ecological Landscape Patterns of Xiaohegou Nature Reserve
}

\author{
Chao Zhang ${ }^{1,2}$, Shuang Wu ${ }^{3}$, Dan Zhao, ${ }^{1,2}$, Quan Guo ${ }^{4}$, Peihao Peng ${ }^{1,2 *}$ \\ ${ }^{1}$ College of Earth Sciences, Chengdu University of Technology, Chengdu, 610059, China \\ ${ }^{2}$ Institute of Ecological Resources and Landscape Architecture, \\ Chengdu University of Technology College, Chengdu, 610059, China \\ ${ }^{3}$ Sichuan Provincial Academy of Surveying Engineering Coalfield, Chengdu, 610072, China \\ ${ }^{4}$ College of Environment \& Ecology, Xiamen University, Xiamen, 361002, China
}

\author{
Received: 26 November 2014 \\ Accepted: 11 January 2015
}

\begin{abstract}
Discovering how to best protect one of the most endangered animals in the world, giant pandas, has always been an important project in ecological studies. Moreover, researching the living environments of giant pandas and how to recover them is one of the most important elements to these studies. In order to more effectively protect the giant pandas and their habitats, we studied the changing of Xiaohegou nature reserve landscape for 20 years, from 1994 to 2014, based on the landscape ecology theory and "3S" techniques (geographic information systems, GIS; remote sensing, RS; global navigation satellite system, GNSS). Specifically, this paper analyzes factors such as landscape fragmentation, connectivity, disturbance degree, landscape diversity, etc. Accordingly, the research presented divides giant panda habitat into nine landscape types that include: evergreen deciduous broad-leaved mixed forest, secondary broadleaved forest, mixed coniferous and deciduous broad-leaved forests, and coniferous forest, et al. The results show that:

1) before establishing the Xiaohegou Nature Reserve in 1993, deforestation was a serious problem, as the results from the 1994 landscape fragmentation suggest.

2) Logging was rampant before the implementation of the national natural forest protection project that began in 1998. Severe damage was observed on the coniferous forest in giant panda habitat. Yet, from the high level of fragmentation that was observed in the connectivity of giant panda habitat, the results suggest 1994 was the worst. After more than ten years of recovery, from 2001 to 2014, the situation of regarding the habitat's connectivity appears better than previous years.

3) The habitat has been impacted heavily by human disturbance from 1994 to 2001, although it has shown a slight decrease in this tendency from 2001 to 2014.

4) In the past 20 years, both the diversity and evenness indexes are showing a slow drop tendency.

5) This paper analyzes the changing situation regarding the land category evolution of giant panda habitats. Coniferous forests, the main habitat of giant pandas, decreased $6.37 \mathrm{hm}^{2}$ during these 5 years, with a rate of decrease at $1.27 \mathrm{hm}^{2}$ per annum from 1994 to 1998. In the years that followed, however, the coniferous forest recovered $4.21 \mathrm{hm}^{2}$ over the course of 15 years at the rate of $0.28 \mathrm{hm}^{2}$ per annum from 1999 to 2014, providing a reference for further nature reserve policy development.
\end{abstract}

Keywords: landscape pattern, evolution, ecological, "3S" techniques, Xiaohegou Nature Reserve

\footnotetext{
*e-mail: peihaop@163.com
} 


\section{Introduction}

In the last 40 years the global number of nature reserves has increased quickly, numbering to upwards of 100,000. Together, these natural reserves cover an area of $18.8 \times 10^{6}$ $\mathrm{km}^{2}$, which accounts for $12.65 \%$ of the world's land area [1]. This growth has great practical significance for the conservation of species and ecosystems. Xiaohegou reserve, set up in 1993, is one of these natural reserves. Around it lies the Songpan Huanglong and Songpan Longdishui nature reserves, and Wanglang and Xuebaoding national preserves. These nature reserves primarily protect giant pandas and their ecological systems. They also provide the basis for studying the species. Furthermore, this sample is comprised of a full giant panda protection system in the Minshan Mountains. Meanwhile, this area is representative of biological community types and acts as a very important geographical location. This location also appears to be an important transition zone between panda species A and B [2]. The area belongs to the Himalayan-Hengduan Mountains, one of the core global biodiversity areas. The reserve maintains typical natural ecological systems and this one in particular is the most intact ecosystem within its latitude region. It has representation and typicality that is outstanding on a global scale [3].

According to existing studies [4-9], there is an increasing interest in using ecological landscape patterns to study nature reserves. For this region's habitat landscape pattern, however, an evolution analysis was not reported. This paper applies the theory of landscape ecology and is supported by " $3 \mathrm{~s}$ " technology. We used Landsat TM/ETM image data for the raw data with a time span of 20 years. An analysis of the spatial distribution and the structure characteristics of the landscape in the study area and the landscape pattern evolution was recorded from 1994 to 2014 using patch numbers, area, fractal dimension, shape index, diversity, dominance, fragmentation degree, evenness, etc. It aims to provide the guide for the sustainable development of giant panda protection in the area and the surrounding ecological environments. This in turn will provide important references for giant panda habitat protection.

\section{General Situation of the Study Region}

The Xiaohegou nature reserve is located in the northwest Sichuan Hengduan Mountains and extends into the northeast section of the Minshan Mountain range to the south, which belongs to Pingwu County. The latitude and longitude coordinates for this region are: E: $104^{\circ} 08^{\prime} 00^{\prime \prime}$ $104^{\circ} 30^{\prime} 10^{\prime \prime}, \mathrm{N}: 32^{\circ} 29^{\prime} 20^{\prime \prime} \sim 32^{\circ} 43^{\prime} 25$ '. The total area is about $138 \mathrm{~km}^{2}$ before the reserve expansion in 2001. After the expansion, the total area grew to approximately $282 \mathrm{~km}^{2}$ and serves as the dividing line between China's Palearctic and Oriental regions. The terrain in the northwest is high while that in the southeast is much lower. The highest altitude is $4,166 \mathrm{~m}$ (Dongyunba) and the lowest is $1,310 \mathrm{~m}$ (Wucengling). There are rising mountain, deep rivers, lush forests, and diverse terrain, as well as abundant animal and plant resources in this area. The low mountain valley area belongs to the subtropical humid monsoon climate, which typically sees short summers and long winters with mild climate, abundant rainfall, sunny weather, and a fairly clear four seasons. The alpine zone, by contrast, is a temperate climate with high rainfall and insufficient sunshine, and suffers from difficult points throughout the four seasons. The comprehensive vegetation development protection zones reflect the characteristics of the northwest Sichuan mountain vegetation distribution. There are about 30 giant pandas in protected areas. Each panda on average only occupies $8.77 \mathrm{~km}^{2}$ of habitat, which is the highest panda density in the Minshan Mountains [3].

\section{Methodology}

\section{Data Sources and Process}

According to the remote sensing image data available from the reserve, we were able to monitor the various stages of development and select the land resources series satellite (Landsat) in 1994, 2001, and 2014. We studied the remote sensing image data and vector files from these three periods in order to better understand the evolved landscape pattern. Pre-processing has allowed us to utilize image corrections, clippings, and color of uniformity, etc. (Fig. 1).
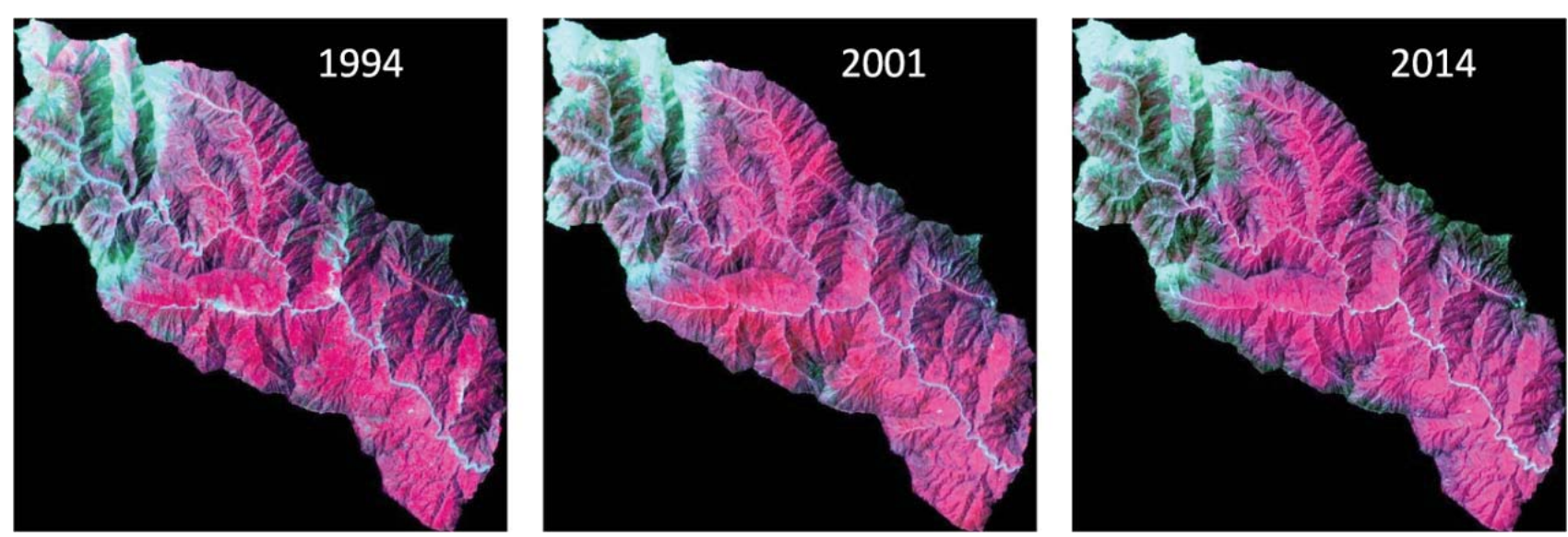

Fig. 1. The third phase of the remote sensing image (false color) in Xiaohegou Nature Reserve. 


\section{Classification Scheme}

Landscape, as used in this study, refers to the surface of an area, specifically how it is geologically and significantly different from other regional characteristics, which is closely related to land use/cover. Land use/cover refers to changes in the area affecting the landscape structure, function, and dynamics of the most common dominant factor (references to the U.S. Geological Survey classification system [10]). The studies by Hu et al. and others are referenced. Their findings, such as the classification the nature reserves and the major locations of panda activities, are used in this study [3]. Considering the situation of remote sensing image characteristics and Xiaohegou Nature Reserve land use actual situation, habitat classifications of the studied area are divided into nine types of landscape. These include: evergreen and deciduous broad-leaved mixed forest (T1), secondary broad-leaved forest (T2), mixed coniferous and deciduous broad-leaved forests (T3), coniferous forest (T4), shrub (T5), meadows (T6), flowstone beach sparse vegetation (T7), cutting-blank (T8), and river and road (T9). Xiaohegou roads are commonly built along the river. Thus we generally merged the two classes typically referred to as the river road. The specific classifications are shown in Fig. 2.

\section{Analysis Methodology}

Patterns and processes are key to Xiaohego landscape change analysis. Accordingly, the landscape index is the basic method of landscape pattern quantitative research [11]. In order to correctly analyze and evaluate the effect of a particular protection environment within a protected area, much international research is used to contrast reserves established before and after a particular time or to contrast reserves inside and outside two specific ways to carry on. The literature review of Nagendra is an example of this latter method [12]. The study selection from the 1994 reserve has been set up until 2014 on the time scale. Remote sensing data from 1994 can, to some extent, reflect the landscape of the area before the reserve was established, whereas the remote sensing data from 2014 may reflect the latest situation regarding the reserve area.

We unified the area that the nature reserve originally designated as the range of dimension analysis on the space. The article selects index such as total (class) area (CA), the number of patches (NP), contagion index (CONTAG), percentage of landscape (PLAND, largest patch index (LPI), edge density (ED), etc., and uses these 12 landscape indices to study the characteristics of Xiaohegou and its change in area, shape, diversity, and fragmentation, as well as its change of space configuration, etc., as seen in Table 1 [13]. The landscape index was calculated by using a Fragstats 4.2 (Dr. Kevin McGarigal) implementation. The landscape spatial pattern index can describe the quantity and spatial characteristics of particular landscape spatial patterns and can help determine the impact factor evolution, which improves the ability to predict the trajectory of landscape structure changes [14].
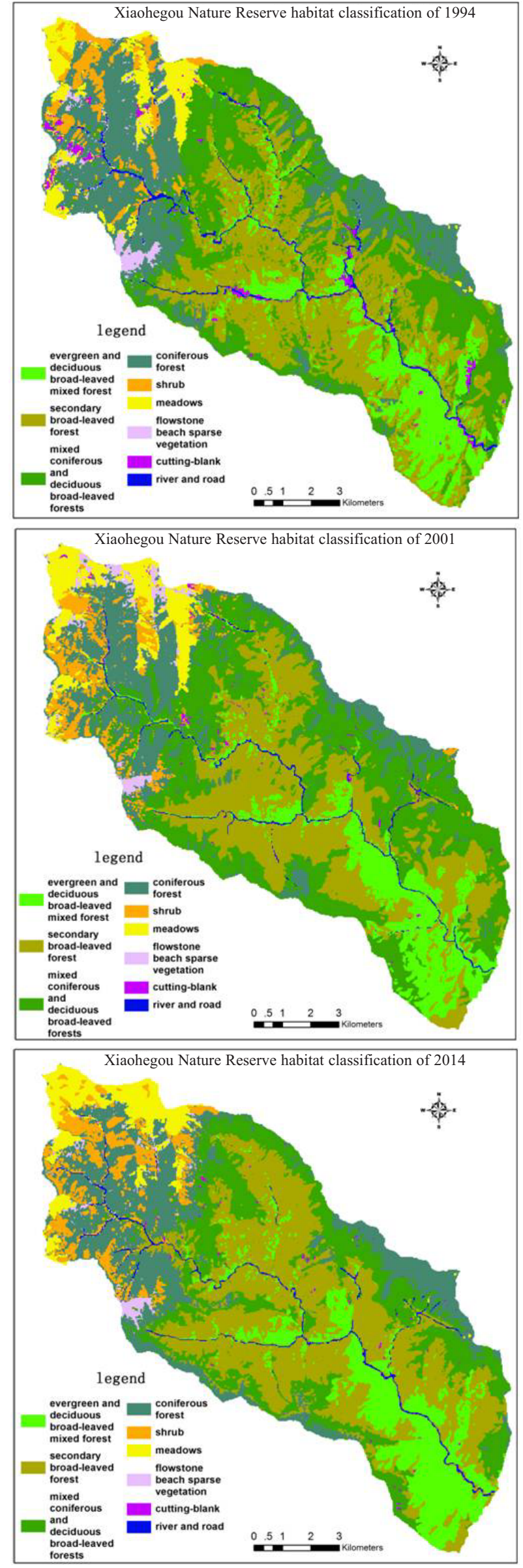

Fig. 2. Xiaohegou Nature Reserve habitat classification. 
Table 1. The main landscape pattern analysis index.

\begin{tabular}{|c|c|c|c|}
\hline Type & \multicolumn{2}{|l|}{ Math } & Remarks \\
\hline $\begin{array}{l}\text { Total (Class) Area } \\
\text { (CA) }\end{array}$ & \multicolumn{2}{|l|}{$C A=\sum_{j=1}^{n} a_{i j}$} & The area of patch "ij" is $a_{i j}$ \\
\hline $\begin{array}{c}\text { Percentage of } \\
\text { Landscape (PLAND) }\end{array}$ & \multicolumn{2}{|l|}{ PLAND $=p_{i}=\frac{\sum_{j=1}^{n} a_{i j}}{A} \times 100$} & $\begin{array}{l}p_{i} \text { is patch type } i \text {, accounting for the proportion of the } \\
\text { whole landscape patches; } A \text { is total area of the landscape }\end{array}$ \\
\hline $\begin{array}{l}\text { Largest Patch Index } \\
\text { (LPI) }\end{array}$ & \multicolumn{2}{|l|}{$\mathrm{LPI}=\frac{\max \left(\mathrm{a}_{\mathrm{ij}}\right)}{\mathrm{A}} \times 100$} & $\begin{array}{l}\text { The area of patch "ij" is } \mathrm{a}_{\mathrm{ij}} \text {; } \mathrm{A} \text { is total area of the land- } \\
\text { scape }\end{array}$ \\
\hline Edge Density (ED) & \multicolumn{2}{|l|}{$\mathrm{ED}=\frac{\sum_{\mathrm{k}=1}^{\mathrm{m}} \mathrm{e}_{\mathrm{ik}}}{\mathrm{A}}$} & $\begin{array}{l}e_{i k} \text { is the total length of the edge for landscape of the cor- } \\
\text { responding types of patch; } A \text { is total area of the landscape }\end{array}$ \\
\hline Patch Density (PD) & \multicolumn{2}{|l|}{$\begin{array}{l}\mathrm{PD}=\frac{\mathrm{ni}}{\mathrm{A}} \times 100 \quad(\text { class }) \\
\mathrm{PD}=\frac{\mathrm{N}}{\mathrm{A}} \times 100 \quad(\text { land })\end{array}$} & $\begin{array}{l}\mathrm{n}_{\mathrm{i}} \text { is type } \mathrm{i} \text { of patch in landscape containing a number of } \\
\text { patches; } A \text { is total area of the landscape; } N \text { is total num- } \\
\text { ber of patches }\end{array}$ \\
\hline $\begin{array}{l}\text { Landscape Shape } \\
\text { Index (LSI) }\end{array}$ & \multicolumn{2}{|l|}{$\begin{aligned} \text { LSI } & =\frac{e_{i}}{\operatorname{mine}_{i}}(\text { class }) \\
\text { LSI } & =\frac{E}{\operatorname{minE}}(\text { land })\end{aligned}$} & $\begin{array}{l}\mathrm{e}_{\mathrm{i}} \text { is the patch type } \mathrm{i} \text { 's total length of the edge; } \text { mine }_{\mathrm{i}} \text { is } \\
\text { the minimum possible values for } \mathrm{e}_{\mathrm{i}} \text {; } \mathrm{E} \text { is landscape's } \\
\text { total edge length minE is the minimum possible values } \\
\text { for } \mathrm{E}\end{array}$ \\
\hline $\begin{array}{l}\text { Shannon's Diversity } \\
\text { Index (SHDI) }\end{array}$ & \multicolumn{2}{|l|}{ SHDI $=-\sum_{i=1}^{m}\left(p_{i} \log _{2} p_{i}\right)$} & $\begin{array}{l}\mathrm{p}_{\mathrm{i}} \text { in landscape is Area of the proportion of patch type } \mathrm{i} \\
\mathrm{m} \text { is patch type number in landscape }\end{array}$ \\
\hline $\begin{array}{l}\text { Splitting Index } \\
\quad \text { (SPLIT) }\end{array}$ & \multicolumn{2}{|l|}{$\operatorname{SPLIT}=\frac{\mathrm{A}^{2}}{\sum_{\mathrm{j}=1}^{\mathrm{n}} \mathrm{a}_{\mathrm{ij}}^{2}}$} & $\begin{array}{l}\text { The area of patch "ij" is } \mathrm{a}_{\mathrm{ij}} \text {; } \mathrm{A} \text { is total area of the land- } \\
\text { scape }\end{array}$ \\
\hline Contagion (CONTAG) & $=1+\sum_{i=1}^{m} \sum_{k=1}^{m} \frac{i j\left(\frac{g_{i k}}{\sum_{k=1}^{m} g_{i k}}\right) \cdot \ln \left(\frac{g_{i k}}{\sum_{k=1}^{m} g_{i k}}\right)}{2 \ln (m)}$ & $(100)$ & $\begin{array}{l}\mathrm{p}_{\mathrm{i}} \text { in landscape is Area of the proportion of patch type } \mathrm{i} \\
\mathrm{g}_{\mathrm{ik}} \text { is node number based on the method of double } \\
\text { between patch type } \mathrm{I} \text {; and patch type } \mathrm{k} \text {; } \mathrm{m} \text { is patch type } \\
\text { number in landscape }\end{array}$ \\
\hline $\begin{array}{l}\text { Fractal Dimension } \\
\text { Index (FRAC) }\end{array}$ & $\mathrm{FRAC}=\frac{2 \ln \left(\frac{\mathrm{p}_{\mathrm{ij}}}{4}\right)}{\ln \left(\mathrm{a}_{\mathrm{ij}}\right)}$ & & $\begin{array}{l}\text { The perimeter of patch "ij" is pig the area of patch "ij" is } \\
a_{i j}\end{array}$ \\
\hline
\end{tabular}

\section{Results and Analysis}

\section{Evolution of Habitat Vegetation Characteristics}

According to the 1994 landscape structures, each type of patch area, in a sequence from small to large, demonstrated that the cutting-blank $<$ flowstone beach sparse vegetation $<$ river and road $<$ shrub $<$ meadows $<$ evergreen and deciduous broad-leaved mixed forest $<$ coniferous forest $<$ mixed coniferous and deciduous broad-leaved forests $<$ secondary broad-leaved forest. By 2001 the landscape structures changed, revealing the following sequence: cutting-blank $<$ river and road $<$ flowstone beach sparse vegetation $<$ shrub $<$ meadows $<$ evergreen and deciduous broad-leaved mixed forest $<$ coniferous forest $<$ secondary broad-leaved forest $<$ mixed coniferous and deciduous broad-leaved forests. In 2014 the sequence indicated that the cutting-blank $<$ flowstone beach sparse vegetation $<$ river and road $<$ meadows $<$ shrub $<$ evergreen and deciduous broad-leaved mixed forest $<$ coniferous forest $<$ mixed coniferous and deciduous broad-leaved forests $<$ secondary broad-leaved forest $<$ mixed coniferous and deciduous broad-leaved forests and secondary broad-leaved forests are proportionally the most prevalent landscape types found in the study area (Fig. 3).

According to the research results of $\mathrm{Hu}$ Jinchu [3], nature reserves identified as evergreen and deciduous broad-leaved mixed forest have a distribution between 1310 2000 m; secondary broad-leaved forest have a distribution between 1350 2500 m; mixed coniferous and deciduous broad-leaved forests have a distribution between

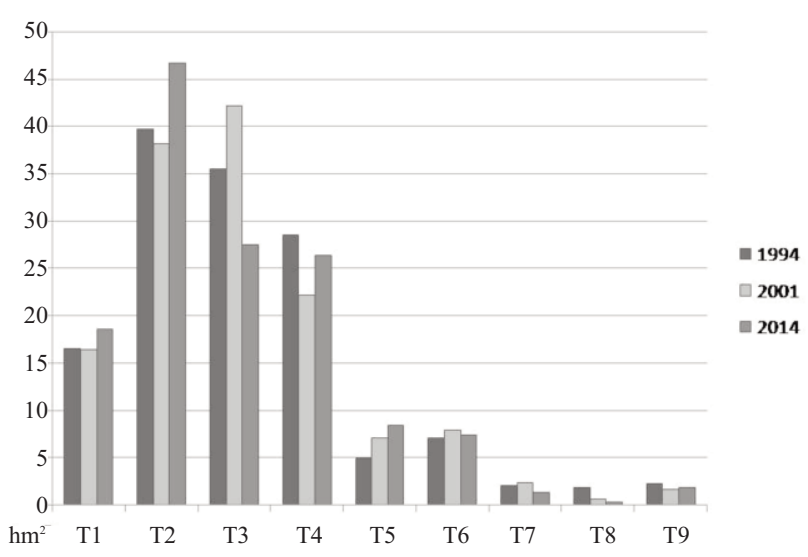

Fig. 3. 1994-2014 reserve habitat area histogram. 
Table 2. Xiaohegou Nature Reserve third phase CA and PLAND values.

\begin{tabular}{|c|c|c|c|c|c|c|}
\hline & \multicolumn{2}{|c|}{1994} & \multicolumn{2}{c|}{2001} & \multicolumn{2}{c|}{2014} \\
\hline Type & CA/hm ${ }^{2}$ & PLAND & CA/hm ${ }^{2}$ & PLAND & CA/hm ${ }^{2}$ & PLAND \\
\hline 1 & 16.569 & 11.9635 & 16.3899 & 11.8342 & 18.5706 & 13.4087 \\
\hline 2 & 39.7125 & 28.674 & 38.1708 & 27.5608 & 46.6677 & 33.6959 \\
\hline 3 & 35.5041 & 25.6354 & 42.2064 & 30.4747 & 27.54 & 19.885 \\
\hline 4 & 28.5066 & 20.5829 & 22.1373 & 15.984 & 26.3484 & 19.0246 \\
\hline 5 & 4.9482 & 3.5728 & 7.0677 & 5.1032 & 8.3943 & 6.061 \\
\hline 6 & 7.11 & 5.1337 & 7.9065 & 5.7088 & 7.4286 & 5.3637 \\
\hline 7 & 2.0646 & 1.4907 & 2.3157 & 1.672 & 1.386 & 1.0007 \\
\hline 8 & 1.8072 & 1.3049 & 0.6354 & 0.4588 & 0.2898 & 0.2092 \\
\hline 9 & 2.2743 & 1.6421 & 1.6668 & 1.2035 & 1.8711 & 1.351 \\
\hline
\end{tabular}

2000 2500 m; coniferous forest have a distribution between 2500 3300 m; meadows and shrub generally have a distribution higher than $3300 \mathrm{~m}$. The Giant panda's habitable region is generally between $2600 \sim 3500 \mathrm{~m}$. Therefore, if we do not consider the slope, slope direction, distance to water resources, and other factors, and only consider forest, coniferous forest is the most suitable habitat for pandas in Xiaohegou, while the secondary broad-leaved forest in high elevation regions serves as a secondary option. $\mathrm{Hu}$ et al. investigated the nature reserve in 2003 and found that the staple food for the giant panda in the protection zones, bamboo, grew well. The pandas' habitat is over $90 \%$ of the total area of the reserve, excluding only a few steep areas [3]. Thus this study uses none types of classification, which mainly is the vegetation as the panda's habitat.

\section{Evolution Analysis of Giant Panda Habitat Species' CA Value}

As shown in Table 2, there is an increasing percentage of mixed coniferous and deciduous broad-leaved forests, growing from 1994 to 2001, reaching a maximum of $42.2064 \mathrm{hm}^{2}$ in 2001 , which is then reduced to $27.54 \mathrm{hm}^{2}$ in 2014. Secondary broad-leaved forests went from $40.1445 \mathrm{hm}^{2}$ in 1994 down to its lowest point, 38.1708 $\mathrm{hm}^{2}$, in 2001, and then was restored to a new high, 46.9026 $\mathrm{hm}^{2}$, in 2014. The coniferous forest, which was covering an area of $28.5066 \mathrm{hm}^{2}$ in 1994, reached its minimum, $22.1373 \mathrm{hm}^{2}$, in 2001 , and in 2014 returned to 26.3484 $\mathrm{hm}^{2}$. From 1994 to 2014, evergreen and deciduous broadleaved mixed forests covering an area's value of the three years in turn is $16.569 \mathrm{hm}^{2}, 16.3899 \mathrm{hm}^{2}$, and $18.5706 \mathrm{hm}^{2}$. During this course of time a shrub has a tendency to increase and reaches its highest point, $8.3943 \mathrm{hm}^{2}$, in 2014. In the past 20 years, meadows increased about $0.23 \%$ of the total area of the habitat. In that same amount of time, cutting-blank and flowstone beach sparse vegetation decreased respectively by $1.0957 \%$ and $0.49 \%$ of the total area of the habitat.
Coniferous forest, which serves as the main habitat for giant pandas, decreased by $6.3693 \mathrm{hm}^{2}$ in five years from 1994 to 1998 . During this time, the average annual degeneration rate was $1.27386 \mathrm{hm}^{2}$ per year. In the 15 years that followed, from 1998 to 2014, coniferous forest recovered $4.2111 \mathrm{hm}^{2}$. During this time, by contrast, the average annual recovery rate was $0.28074 \mathrm{hm}^{2}$ per year. Accordingly, the degeneration rate is 4.5375 times that of the recovery rate. According to the current recovery rate, without considering recovery quality the area will require 7.69 years to return to the levels originally observed in 1994. Secondary broadleaved forest, which serves as another major habitat for giant pandas, shrank $1.9737 \mathrm{hm}^{2}$ in five years from 1994 to 1998. During this time the average annual degeneration rate was $0.39474 \mathrm{hm}^{2}$ per year. The following 15 years, from 1999 to 2014 , witnessed a $8.7318 \mathrm{hm}^{2}$ recovery of coniferous forest. The average annual recovery rate during this time was $0.58212 \mathrm{hm}^{2}$ per year, meaning that the recovery rate is 1.47469 times that of its degeneration rate. The growth of the secondary broad-leaved forest has a positive significance regarding habitat system restoration. The evolution process of habitat types over a course of 20 years is shown in Fig. 4.

\section{Giant Panda Habitat Species' NP, AREA, MN, and ED Value Evolution Analysis}

As shown in Table 3, mixed coniferous and deciduous broad-leaved forests' NP value is highest when the shrub's NP value is lowest, which is in 1994. Coniferous forest's NP value is highest in 2001. Mixed coniferous and deciduous broad-leaved forests' NP value is highest while the meadows' NP value is its lowest, which is in 2014. According to the data, it appears that coniferous forests suffered serious destruction from 1994 to 2001, producing a severe negative effect on panda habitat. Considering the average patch area, secondary broad-leaved forest's patch area is the largest in 1994 and 2001. In 2014 the secondary broad-leaved forest's patch area was the largest landscape type with the exception of the meadows. To clarify further: 
evergreen and decidous board-leaved mixed forest
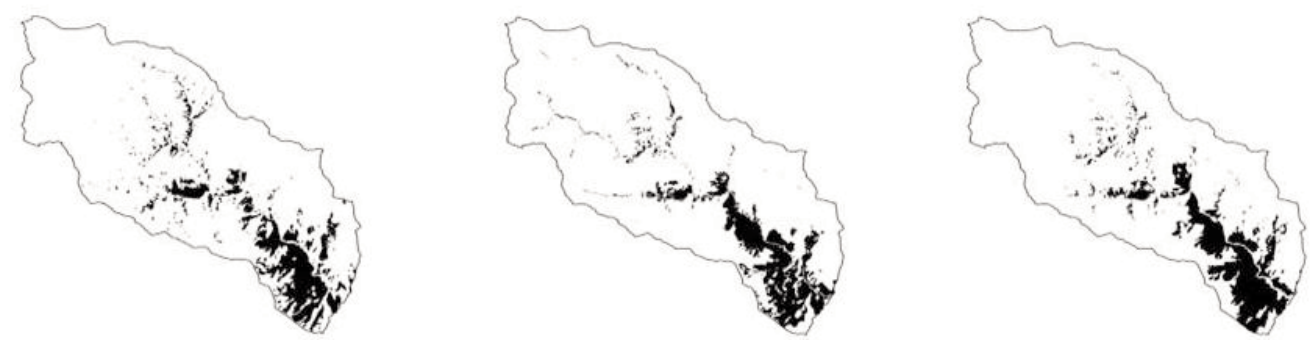

secondary board-leaved forest
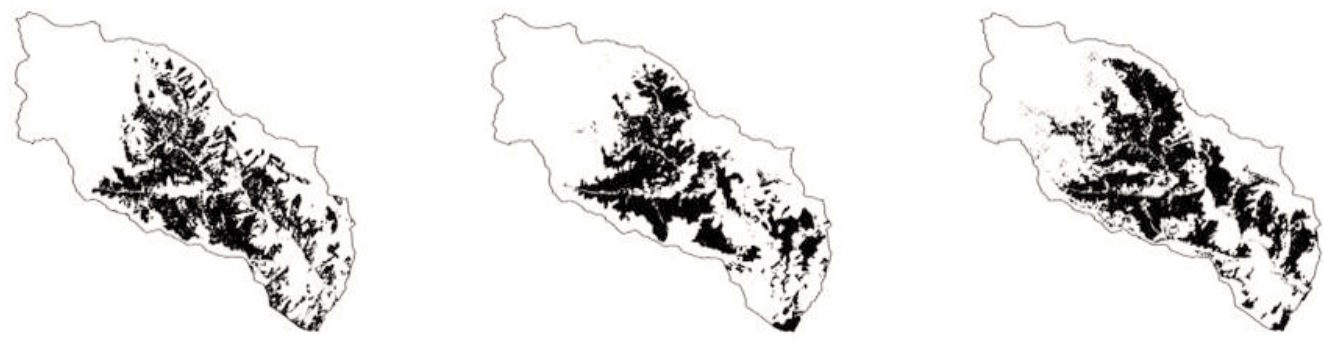

mixed coniferous and decidous board-leaved forests
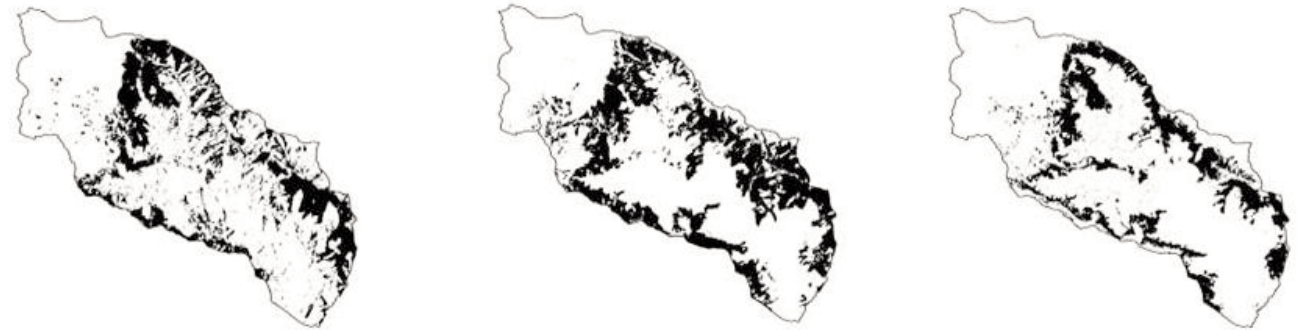

coniferous forest
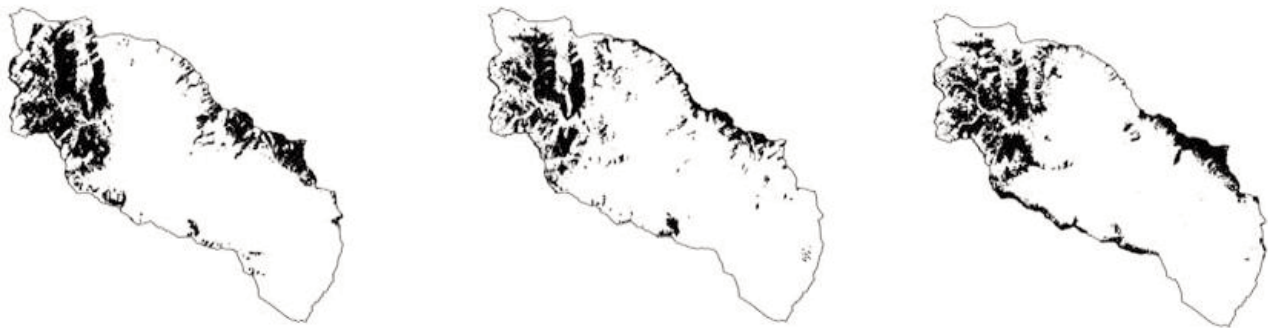

shrub
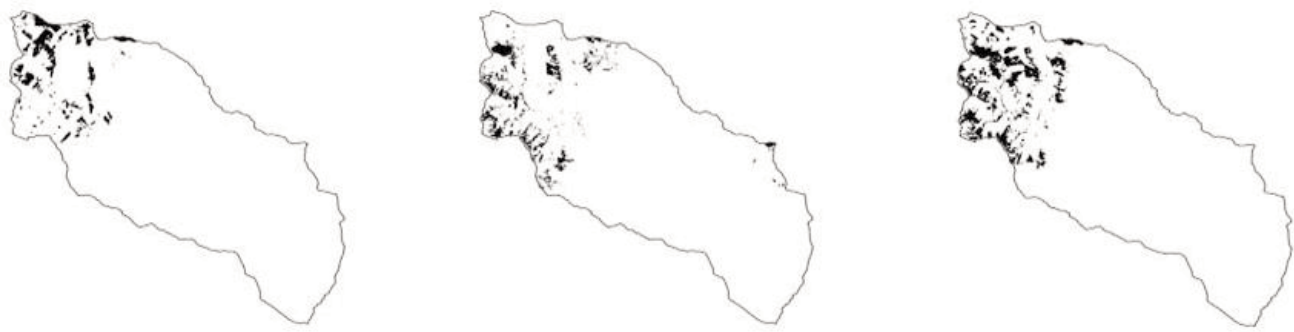

meadows
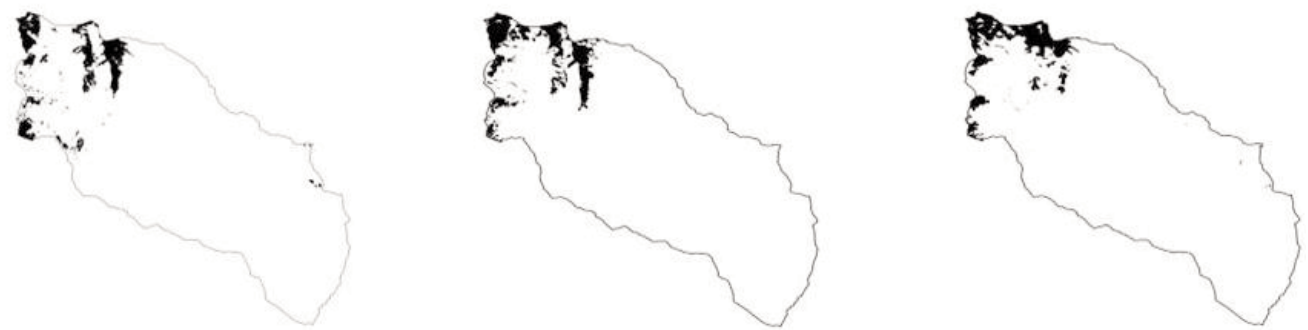

Fig. 4. 20-year evolution of Xiaohegou Nature Reserve habitat types. 


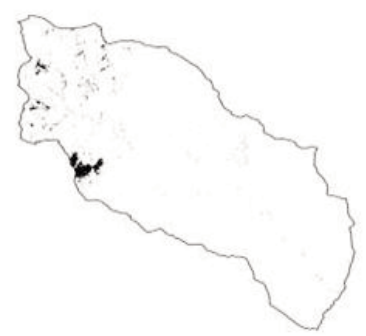

flowstone beach sparse vegetation

cutting-blank

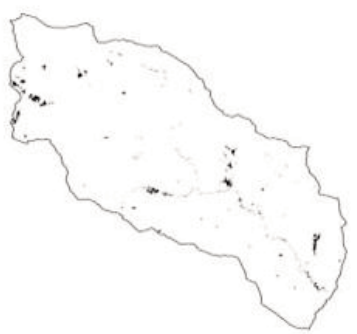

river and

road

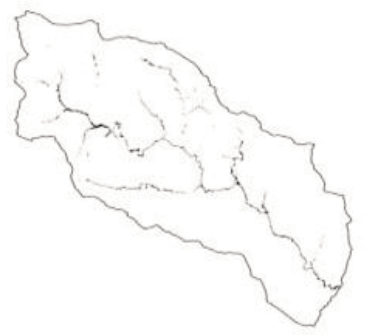

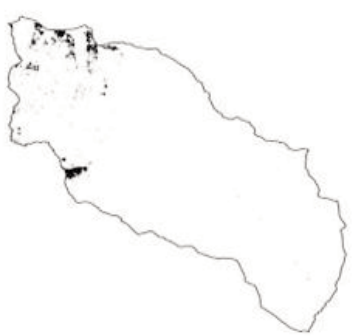
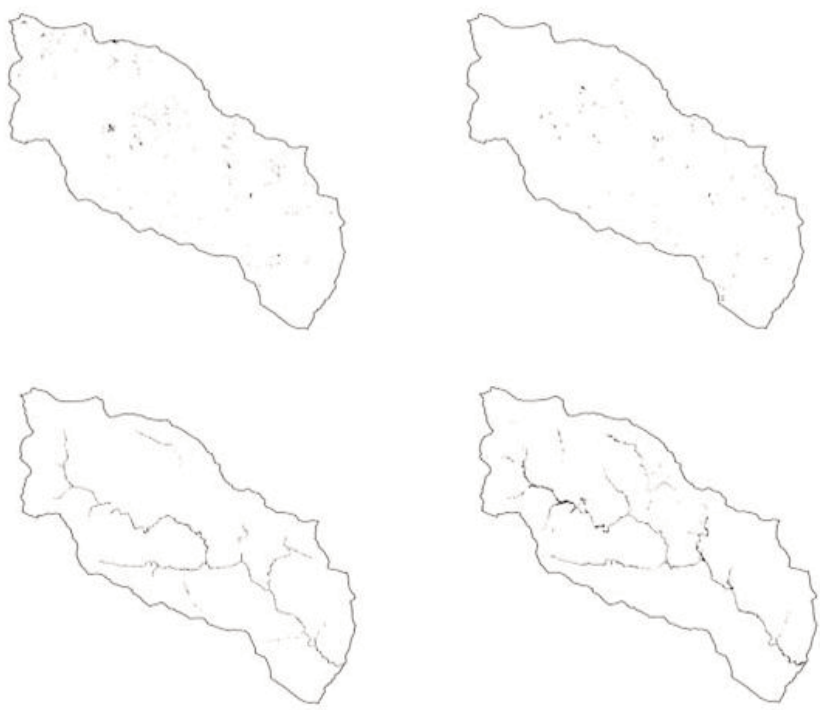

Fig. 4. Continued.

the secondary broad-leaved forest is the most advantaged degree species in the nature reserves.

Considering boundary density observations, the secondary broad-leaved forest takes over the front two position in three-stage images, suggesting that this habitat types has strong openness; accordingly, it is an indispensable channel that interacts with patches of other habitat types to communicate material and energy. Therefore, secondary broadleaved forests greatly influence giant panda behaviors such as migration and foraging, etc.

\section{Giant Panda Habitat Species'FRAC, AM, and PD Value Evolution Analysis}

Table 4 shows a numerical fractal dimension analysis of the landscape types. The results suggest that the various shapes of the patches in the study area are relatively regular. This pattern means that the degree of man-made influence is serious. The fractal dimension minimum value of shrub, evergreen, and deciduous broad-leaved mixed forest, and mixed coniferous and deciduous broad-leaved forests appeared in 1994, which shows that the influence of human activities on the above tree species is big [15]. The minimum fractal dimension for meadows, coniferous forest, and secondary broad-leaved forest landscapes appeared in 2001. This illustrates that from the establishment of the reserve in 1993 until 2001, there were no strict limitations on human activities. These human activities mainly affected the tree species and meadows in the research area, which showed a disruptive effect on trees and the possible presence of grazing. The minimum value of cutting-blank's fractal dimension appeared in 2014. The gradual reduction of cutting-blank area indicates there is the possibility of artificial reseeding.

The minimum value of flowstone beach sparse vegetation fractal dimension appeared in 2014 as well, indicating that during a recent period of time the habitat types are vulnerable to human disturbance. Because of its dominance between the variety of habitat types, the fractal dimension value of secondary broad-leaved forest is largest, and the man-made influence degree is minimal. By contrast, the cutting-blank habitat type depends entirely on the human activities, so the fractal dimension value is minimum. In addition, the degree of fragmentation is at its maximum PD value in 1994 for the meadows, flowstone beach sparse vegetation, evergreen and deciduous broad-leaved mixed forest, mixed coniferous and deciduous broad-leaved forests, cutting-blank, and the river and roads. Among these habitat types, mixed coniferous and deciduous broadleaved forests' PD values are the largest.

This trend illustrates that in 1994 mixed coniferous and deciduous broad-leaved forests suffered serious destruction. Shrub and coniferous forest's maximum PD value appeared in 2001. Table 4 also shows that from 1994 to 
Table 3. Xiaohegou Nature Reserve third-phase ED, NP, and AREA_MN values.

\begin{tabular}{|c|c|c|c|c|c|c|c|c|c|}
\hline & \multicolumn{3}{|c}{1994} & \multicolumn{3}{|c|}{2001} & \multicolumn{3}{c|}{2014} \\
\hline Type & NP & AREA_MN/hm ${ }^{2}$ & ED & NP & AREA_MN/hm ${ }^{2}$ & ED & NP & AREA_MN/hm ${ }^{2}$ & ED \\
\hline 1 & 348 & 0.047617 & 2129.19 & 226 & 0.072522 & 1919.72 & 236 & 0.078689 & 1682.51 \\
\hline 2 & 233 & 0.172294 & 4873.16 & 182 & 0.20973 & 2888.02 & 359 & 0.130648 & 4211.16 \\
\hline 3 & 760 & 0.045287 & 4551.9 & 323 & 0.137878 & 3967.02 & 384 & 0.070015 & 2859.43 \\
\hline 4 & 241 & 0.120992 & 2758.7 & 308 & 0.069426 & 2835.6 & 311 & 0.086047 & 3051.57 \\
\hline 5 & 100 & 0.04941 & 747.35 & 283 & 0.019387 & 1394.4 & 180 & 0.046635 & 1457.44 \\
\hline 6 & 124 & 0.057339 & 871.48 & 102 & 0.077515 & 820.57 & 56 & 0.132654 & 549.36 \\
\hline 7 & 353 & 0.005849 & 695.58 & 207 & 0.011187 & 648.79 & 232 & 0.005974 & 503.43 \\
\hline 8 & 261 & 0.006924 & 679.11 & 244 & 0.002604 & 385.37 & 77 & 0.003764 & 150.77 \\
\hline 9 & 163 & 0.013953 & 996.03 & 94 & 0.017732 & 823.17 & 129 & 0.014505 & 906.35 \\
\hline
\end{tabular}

2001, destructive human activities continued throughout the period. The coniferous forest habitat type suffered the most damage. Overall, it is around the year 2001 that humans caused the most damage to giant panda habitats, as indicated by the negative effect on the giant panda habitation. The PD value of secondary broad-leaved forests is the largest in 2014, which means there exists the possibility of mutual infiltration between secondary broad-leaved forest and other types of habitats. Many other reasons can affect the landscape of giant panda habitat, for example earthquakes, forest fires, landslides, etc. However, our field survey and comprehensive literature review suggest that the most important factor is human activity [3].

\section{Evolution of the Whole Habitat Characteristics}

Before setting up the reserve in 1993, many forests were destroyed [3], thus disrupting the matrix by creating a large number of landscape patches. In 1994 there were 2,648 patches; because of the large number of patches, this is an inhospitable environment for the giant pandas' migration, feeding patterns, and other activities.

From 1994 to 2001 the mixed coniferous and deciduous broad-leaved forests inside the reserve area expanded gradually, causing the total number of patches to be reduced from 2,648 patches in 1994 to 1,890 in 2001. Although the number of overall patches decreased, the corridor quantity increased. The expansion of the mixed coniferous and deciduous broad-leaved forests comes at the cost of the original coniferous forest, because loggers have cut down a large number of coniferous forests and plant broadleaf forests, thus destroying the coniferous forests, which are the original habitat in which giant pandas lived. Thus the giant pandas' condition worsened. From 2001 to 2014, due to the reserve's internal stability, the number of patches increased slowly to 1,995 patches by 2014 (Table 5). The reserve also experienced a large number of secondary broad-leaved forest growth and development. Mixed coniferous and deciduous broad-leaved forests have replaced the surrounding various kinds of classes, so the number of overall patches has slightly increased. During this period, despite the increase in the total number of patches and reduction in the corridors, the impact on the habitat of the species was reduced because of the mitigation of human destruction. This in turn leads to good development for giant panda habitat.

\section{Evolution Analysis of Giant Panda Habitat Fragmentation}

Before the establishment of the 1993 reserve, landscape fragmentation was on the highest degree level due to serious reserve deforestation rates. The PD value was 19.1196 in 1994. To address the giant pandas' habitat degradation and fragmentation, we suggest that artificial restoration measures are an essential part of any habitat restoration method [16]. After a reserve has been set up, staff members should plant an artificial broad-leaved forest that could spur mixed coniferous and deciduous broad-leaved forest development and reduce the number of patches in areas where a large number of trees have been felled. Thus the fragmentation status will also be reduced.

The PD values in the study area were 13.6466 in 2001, which is the lowest of the three periods. However, because much of the original coniferous forest in the panda habitat was destroyed, it will take a while for the planted artificial broadleaf forest to provide a suitable replacement habitat. At this time the fragmentation reduced rather than improved the giant pandas' habitat, so the habitat system was severely damaged.

By 2014 the reserve had had 10 years of recovery. Along with the mixed coniferous and deciduous broadleaved forest patches, other types of vegetation were introduced, which causes the degree of fragmentation degree to slightly increase. At this time, the PD value was 14.4047. The secondary broadleaved forest expanded, thus leading to the less discrete landscape patches, so the reserve habitat is more stable now. 
Table 4. Xiaohegou Nature Reserve third-phase PD and FRAC_AM values.

\begin{tabular}{|c|c|c|c|c|c|c|}
\hline & \multicolumn{2}{|c|}{1994} & \multicolumn{2}{|c|}{2001} & \multicolumn{2}{|c|}{2014} \\
\hline Type & PD & FRAC_AM & PD & FRAC_AM & PD & FRAC_AM \\
\hline 1 & 2.5127 & 1.1537 & 1.6318 & 1.2218 & 1.704 & 1.1575 \\
\hline 2 & 1.6968 & 1.2954 & 1.3141 & 1.2223 & 2.1806 & 1.2911 \\
\hline 3 & 5.8557 & 1.2353 & 1.343 & 1.2646 & 3.3286 & 1.2404 \\
\hline 4 & 1.7907 & 1.2333 & 2.4694 & 1.215 & 2.325 & 1.2572 \\
\hline 5 & 0.7581 & 1.1234 & 2.2167 & 1.1819 & 1.2997 & 1.167 \\
\hline 6 & 0.8953 & 1.1595 & 0.7365 & 1.1449 & 0.4043 & 1.1729 \\
\hline 7 & 2.5488 & 1.1307 & 1.4946 & 1.1547 & 1.6751 & 1.1189 \\
\hline 8 & 1.8845 & 1.1006 & 1.7618 & 1.068 & 0.556 & 1.0459 \\
\hline 9 & 1.1769 & 1.2338 & 0.6787 & 1.2452 & 0.9314 & 1.2205 \\
\hline
\end{tabular}

Meanwhile, although the artificial forest has grown and developed within the past 10 years, the new growth cannot be compared to the original forest. Although the reserve has shown signs of improvement, the overall rate for forest reestablishment is still slow. The SPLIT and LSI value changes also support the above conclusion.

\section{Evolution Analysis of the Giant Panda Habitat Connection Degree}

Generally speaking, a high CONTAG value indicates that some landscape patches have formed good connectivity. Conversely, a low CONTAG value implies that the landscape is influenced by a variety of factors, so the degree of landscape fragmentation is higher $[17,18]$. The CONTAG value was 47.2788 in 1994 , which was the lowest rate among the three phases in the study area. The connectivity of the habitat was the worst in 1994, so the whole habitat system has been severely damaged, which has had adverse effects on the migration patterns of the giant pandas.

Xiaohegou Nature Reserve mixed coniferous and deciduous broad-leaved forests between 1994 and 2001. The forest showed rapid development, with a CONTAG value growth rate of 49.2952 in 2001 and an increase in the corresponding degree of connectivity. However, because the original forest system had been destroyed, the suitability of the giant pandas' habitat system has declined. Until 2014 the rate of development remained basically stable, with a CONTAG value growth of 49.7685 . At this time a large number of secondary broad-leaved forests replaced the mixed coniferous and deciduous broad-leaved forests, so the connection degree is better in this habitat. This date indicates that, after years of protection development, the Xiaohegou ecosystem has gradually balanced out and is moving in a positive direction.

The study area's main advantages are its landscapes, because the changes in the smaller landscapes reflect the trends of the whole landscape. Between 1993 and 1998, when the China National Natural Forest Protection Project began, a large number of coniferous forests in reserve were cut down. At the same time, reseeding broadleaf forests causes other problems, such as the expansion of a large number of mixed coniferous and deciduous broad-leaved forests. Between 1994 and 2001 the LPI value changed little, even when the secondary broad-leaved forest infiltrated the rest of the habitats (though the dominance of the new growth was slightly lower in 2001). After several years of diffusion, until the stable recovery period between 2001 and 2014, the secondary broad-leaved forests had absolute advantage, which reached its peak in 2014. Based on this information, we have gathered that the LPI value was 17.0205 in 1994, 16.7547 in 2001, and 29.934 in 2014. Both the CONTAG and the LPI peaked in 2014, which means the spread of the secondary broad-leaved forest has a very important role in the improvement of the internal degree of connection in the habitat, which bodes well for giant panda migration.

\section{Evolution Analysis of Giant Panda Habitat Disturbance Degree}

The range of the landscape fractal dimension values generally should be between 1 and 2; if the value is closer to 1 , then the shape of the patches is simpler and more regular, which shows that the landscape has experienced greater human disturbances. If the value is closer to 2 , then the shapes of the patches are more complex, which indicates fewer disturbances by humans [19-22]. As shown from the calculation results, the FRAC_AM value from 1994 to 2014 was $1.2311,1.2259$, and 1.2396 . Between 1994 and 2001 the rate of human disturbance was greater.

From 2001 to 2014, the FRAC_AM was relatively stable. The slow growth of Xiaohegou Nature Reserve during these years demonstrates a gradual declining trend in terms of human disturbance. Otherwise, the TA and NP values indicate that the reserves' average patch area is relatively small. The SHAPE AM value shows that the patch's shape was more regular in 2001 and more irregular in 2014. 
Table 5. Xiaohegou Nature Reserve habitat features.

\begin{tabular}{|l|c|c|c|}
\hline & 1994 & 2001 & 2014 \\
\hline $\mathrm{TA}\left(\mathrm{hm}^{2}\right)$ & 138.4965 & 138.4965 & 138.4965 \\
\hline $\mathrm{NP}$ & 2648 & 1890 & 1995 \\
\hline PD $\left(\mathrm{n} / \mathrm{hm}^{2}\right)$ & 19.1196 & 13.6466 & 14.4047 \\
\hline SPLIT & 17.0421 & 13.8356 & 8.2977 \\
\hline LSI & 29.4076 & 24.8331 & 24.465 \\
\hline CONTAG & 47.2788 & 49.2952 & 49.7685 \\
\hline LPI & 17.0205 & 16.7547 & 29.934 \\
\hline FRAC_AM & 1.2311 & 1.2259 & 1.2396 \\
\hline SHAPE_AM & 7.7382 & 6.8695 & 8.6982 \\
\hline SHDI & 1.7448 & 1.7246 & 1.7168 \\
\hline SHEI & 0.7941 & 0.7849 & 0.7814 \\
\hline
\end{tabular}

This date also proves that the rate of reserve interference was greater in 2001, with fewer disturbances in 2014. In the past 10 years the protection zones have been placed under control. This issue concerns the surrounding habitats due to the implementation of returning farmland and constructed ecological environments in the planning of the reserve land [23]. For the giant pandas and other wildlife in the protected areas, greater human disturbances create a less suitable living environment.

\section{Evolution Analysis of the Giant Pandas' Habitat Diversity and Uniformity}

Xiaohegou has 22 formations, each a kind of habitat. Inside these habitats different animals have different niches, including streams, swamps, small caves, and other habitats. Habitat diversity gives birth to a rich and diverse plant community. In return, the diversity of the plant community provides a food base for animal communities and habitats [3]. Through calculation and analysis we discovered that Shannon's diversity index was 1.7448 in 1994. In 2001, however, the diversity index was reduced to 1.7246 , which decreased even more in 2014, when the index was measured at 1.7168 .

From 1994 to 2001 the reserve diversity index decreased, partly because of the recently established preserve, which favored mixed coniferous and deciduous broad-leaved forests, causing a massive increase in their numbers within the protected areas. Therefore, diversity decreased during this period because coniferous forests, which are the most suitable for giant pandas, were destroyed, thereby greatly damaging the giant panda habitat system. From 2001 to 2014 the diversity values were either reduced slightly or remained stable. This occurs because the mixed coniferous and deciduous broad-leaved forests, as well as the secondary broad-leaved forest in protected areas, completed their succession of the new to the old, gradually restoring the area's ecological environment. While the diversity of this period declined, the secondary broad-leaved forest growing at high altitudes proved to be a suitable habitat for the giant panda. Although this process is very slow and the role is not obvious, it does have a positive effect on the recovery of the giant panda habitat system. Shannon evenness index (SHEI) also was reduced from 0.7941 in 1994 to 0.7849 in 2001 , and then fell to 0.7814 in 2014 . The slow but steady decrease shows how a species within a large number of growth can cause a loss in uniformity. Whether this decline is good or bad for the giant panda depends on the large increase of habitat types and how appropriate they are for giant pandas. In 2014 habitat uniformity decreased, yet still held a positive significance for the recovery of the giant panda habitat system.

\section{Conclusions}

The Xiaohegou Nature Reserve is one of the most important areas in China's giant panda protection system, rich with unique vegetation types. In order to protect and reasonably use the natural resources within the reserve, this paper discusses the quantitative analysis landscape ecological structure and landscape pattern evolution of this study area based on the latest remote sensing satellite data of Landsat-8 (2014). The results show that secondary broadleaved forests hold an absolute predominance in the study area, with the PLAND value reaching 33.6959\% in 2014. Considering the whole landscape matrix, its stability and distributed rationality plays a major role in suitable giant panda environment growth. The cutting-blank habitat type downsized gradually. When combining this detail with an analysis based on fractal dimension indexes, the results shows that human disturbances are decreasing, which further suggests that closed forest ecology restoration work has been receiving the effect in recent years. Meanwhile, according to the changes in coniferous forests, which greatly influence the giant pandas, we can see that forest destruction is relatively easy and quick, but the recovery process is difficult and long. Therefore, rational planning, distribution, and long-term adherence to the plan also is imperative for Xiaohegou.

The defects in this study include:

1. The remote sensing satellite data was taken from the Landsat; although it is typically very good and currently the most popular model, the accuracy of the image resolution of $30 \mathrm{~m}$ should be improved. With the arrival of open access to the satellite data times, remote sensing images with higher resolution will become more popular so that research results will be more accurate.

2. Limited by data collection conditions, this study involves regions that do not include peripheral villages; thus we cannot create a comprehensive plan and study the influence of human activities in the protected areas. This section should be improved upon and perfected in the future. 


\section{References}

1. NAVEH Z., LIEBERMAN A.S. Landscape ecology, theory and application. New York: Springer-Verlag, 1985.

2. Established pandas' life corridor has been fully affirmed by the experts, 2003.

http://www.cas.cn/ky/kyjz/200310/t20031031_1028049. shtml [In Chinese].

3. JINCHU H. Comprehensive Scientific Survery Report of the Xiaohegou Nature Conservation. Chengdu: Sichuan Science and Technology Press, 2005 [In Chinese].

4. TURNER M.G., O'NEILL R.V., GARDNER R.H., MILNE B.T. Effects of changing spatial scale on the analysis of landscape pattern. Landscape Ecol., 3, (3-4), 153, 1989.

5. RIITTERS K.H., O'NEILL R.V., HUNSAKER C.T., WICKHAM J.D., YANKEE D.H., TIMMINS S.P., JACKSON B.L. A factor analysis of landscape pattern and structure metrics. Landscape Ecol., 10, (1), 23, 1995.

6. GARDNER R.H., MILNE, B.T., TURNEI M.G., O'NEILL R.V. Neutral models for the analysis of broad-scale landscape pattern. Landscape Ecol., 1, (1), 19, 1987.

7. WU J. Effects of changing scale on landscape pattern analysis: scaling relations. Landscape Ecol., 19, (2), 125, 2004.

8. MCGARIGAL K., MARKS B.J. Spatial pattern analysis program for quantifying landscape structure. Gen. Tech. Rep. PNW-GTR-351. US Department of Agriculture, Forest Service, Pacific Northwest Research Station, 1995.

9. SUROVÁ D., PINTO-CORREIA T., MARUŠÁK R. Visual complexity and the montado do matter: landscape pattern preferences of user groups in Alentejo, Portugal. Ann. For. Sci., 71, (1), 15, 2014

10. YOUXU J. Chinese forest community classification and community characteristics. Beijing: China Forestry Publishing, 1998 [In Chinese].

11. ELLIOT N.B., CUSHMAN S.A., MACDONALD D.W., LOVERIDGE A.J. The devil is in the dispersers: predictions of landscape connectivity change with demography. J. Appl. Ecol., 2014
12. NAGENDRA H. Do parks work? Impact of protected areas on land cover clearing $[\mathrm{J}]$. AMBIO: A Journal of the Human Environment, 37, (5), 330, 2008.

13. XINQI Z., MEICHEN F. Landscape spatial analysis technology and application. Beijing: science press, 2010 [In Chinese].

14. QIUJU Z., BOJIE F., LIDING C. Several Problems about Landscape Pattern Change Research. Scientia Geographica Sinica, 23, (3), 264, 2003 [In Chinese].

15. LI J.J., WANG X.R., WANG X.J., MA W.C., ZHANG H. Remote sensing evaluation of urban heat island and its spatial pattern of the Shanghai metropolitan area, China. Ecological Complexity, 6, (4), 413, 2009.

16. CHUN-XIA Q., FU-LIANG Z. Environment of panda's habitat in Qinling region based on ArcView. Journal of Xi'an University Of Science and Technology, 26, (1), 65, 2006 [In Chinese]

17. FORMAN R.T.T., GODRON M. Landscape Ecology. New York: John Wily, 1986.

18. NAVEH Z., LIEBERMAN A.S. Landscape ecology, theory and application. New York: Springer-Verlag, 1985.

19. YANG H.W., KANG D.W., KANG W., LI J., LI J.Q., ZHAO L.J., WANG X.R. Suitability of plantation recovery as the habitat of giant panda. Journal of Beijing Forestry University, 35, (4), 67, 2013.

20. QIANG-FENG L., GUO-LIANG W., GUO-SHENG K. Analysis of landscape spatial pattern of land-use in Mengda Reserve based on GIS. Journal of Central South University of Forestry \& Technology, 31, (12), 65, 2012.

21. HOU Y., BURKHARD B., MÜLLER F. Uncertainties in landscape analysis and ecosystem service assessment. J. Environ. Manage., 127, 117, 2013.

22. YANG G., PU R., ZHANG J., ZHAO C., FENG H., WANG J. Remote sensing of seasonal variability of fractional vegetation cover and its object-based spatial pattern analysis over mountain areas. ISPRS Journal of Photogrammetry and Remote Sensing, 77, 79, 2013.

23. XUEZHI W., WEIHUA X., ZHIYUN O. Impacts of spatiotemporal changes in agricultural land on giant panda habitat: a case study in the Baicaohe watershed of the mid-Minshan Mountains. Biodiversity Science, 17, (1) 10, 2009. 
